\title{
DETERMINANTS OF SUCCESSFUL AGING AMONG PRE-RETIREMENT PUBLIC SERVANTS IN KLANG VALLEY, MALAYSIA
}

\author{
Khairul Rafizah H, Aniza I, Shamsuddin K and Hazlina MM \\ Department of Community Medicine, Medical Faculty, Universiti Kebangsaan Malaysia.
}

Correspondence author: Aniza Ismail

Email: aniza@ppukm.ukm.edu.my

\begin{abstract}
Following the global trend, Malaysia is moving towards an aging population. With the change in age ratio, there will be more age-related diseases and challenges that need to be managed appropriately. This study aimed to determine the prevalence of successful aging (SA) among pre-retirement Malaysian public servants and the predicting factors. $A$ cross-sectional study has been conducted using multistage sampling for selecting four out of 23 ministries and agencies under each respective ministry. Simple random sampling was used to select the state, agencies and respondents. A total respondent of 1,064 pre-retirement public servants (50-60 years old) working in nine federal government agencies within Klang Valley were finally selected. The respondents completed a self-administered questionnaire and their cognitive function was assessed using the Mini-Mental State Examination (MMSE). SA was defined as being able to fulfil all three criterions i.e. absence of six major chronic diseases and having both good physical and psycho-cognitive functions. The prevalence of SA was 37.5\%. Multiple logistic regression showed that the factors with higher odds of having SA were younger age (50-54 years old) (adjusted odds ratio [aOR] 1.32, 95\% confidence interval [CI] 1.01-1.73), being physically active (aOR 1.39, 95\% Cl 1.05-1.84), non-obese (aOR 2.14 , 95\%Cl 1.52-3.02) and good social support (aOR 1.78, 95\% Cl 1.30-2.43). A minority of public servants in this study had SA. We conclude that employers in various agencies should play roles in promoting SA aiming for healthy behaviours and providing healthy working environments.
\end{abstract}

Keywords: Successful aging, pre-retirement, public servants, predictors

\section{INTRODUCTION}

Many countries are now experiencing the global phenomenon termed 'aging population', whereby the older population has begun to outnumber the young population aged below 15 years. The number of older people has been projected to rise more than double from 841 million in 2013 to more than 2 billion in 2050. Meanwhile, Malaysia has been projected to have an aging population by 2020 [1]. With the change in the age ratio, the government faces a higher burden of old agerelated disabilities and socio-economic consequences that need to be managed properly, including in terms of healthcare services. One strategy for reducing the impact is to ensure that a high proportion of the elderly, if not all, achieve successful aging (SA).

This concept of SA was popularized in 1987 [2] who applied biological theory in defining SA which comprises of the absence of chronic diseases and having good physical, mental and social wellbeing among older adults. Meanwhile, various variables have been studied as predictors of SA including behavioural risk factors, physical functioning, social engagement, daily activities, cognitive functions, spiritual aspects [3] and genetics or hereditary factors [4].

A few studies in Malaysia have investigated this aspect, but none involved the younger population. Therefore, this study was undertaken to determine the prevalence and predicting factors of SA among pre-retirement age group public servants in Klang Valley, Malaysia. It is hoped that the findings can assist public health personnel in carrying out strategies specifically for the pre-retirement age population to prepare them for SA.

\section{METHODS}

This cross-sectional study was conducted from July until December 2018 and involved 1,064 public servants in the pre-retirement aged group (aged 50 to 60 years) working at nine government agencies within Klang Valley (which includes Selangor state and the Kuala Lumpur Federal Territory).

Sample size was calculated using Power and Sample Size Programme (PS2) and it was based on two (2) previous articles which were a local study by Hamid TA, Momtaz YA \& Ibrahim R (2012) and also a study among civil servants by Severine et al. (2012). The initial calculated sample size was 887 . However, a higher number of the sample size was targeted to cover for any incomplete data, possible exclusions, drop out and the need to carry out subgroup analysis, thus the final calculated sample size is 1,064 .

Multistage sampling was applied, where simple random sampling was used for selection of state, four of 23 available ministries and subsequently 
the agencies to represent each ministry. At the final stage within each selected agency, selection of individual respondents was done using simple random sampling.

The respondents were asked to complete a selfadministered questionnaire and their cognitive function was subsequently assessed using MiniMental State Examination (MMSE). Some of the questions were adapted from previous studies and had undergone translation from the original English into Malay, as well as pre-testing, validity and reliability testing prior to usage. Cronbach's alpha test was used and the minimum acceptable value was 0.7 . Factor loadings for all the items in the questionnaire were more than 0.4 .

The dependent variable was operationalized, based on the 1987 model [2]. Respondents were categorized as SA only if they fulfilled all three criterions: 1) no major chronic diseases (selfreported to not having any of the six diseases, i.e. diabetes mellitus, hypertension, stroke, chronic lung diseases, cancer and heart problems); 2) good physical functioning; and 3) good psycho-cognitive functioning.

For the physical function assessment, the respondents were required to rate their difficulty in performing nine physical tasks without using supportive equipment: walking 400 meters $(1 / 4$ mile); walking up 10 steps without resting (climbing) and standing for 2 hours; sitting for 2 hours; bending, bowing or kneeling; reaching or reaching something above the head; using fingers to hold or handle small objects; lifting or carrying an object weighing $4.5 \mathrm{~kg}$; and pushing or pulling large objects. Ratings were based on a scale, i.e. unable to do it directly, very difficult, quite difficult, slightly difficult and not difficult at all. Those who answered not difficult at all, slight difficulty or quite difficult were categorized as having good physical function [5].

The respondents' psychological function was assessed using the Malay version 21-item Depression Anxiety Stress Scale (DASS-21) questionnaire and scoring [6]. Those who had score results between normal and mild categories were deemed to have good psychological function. For cognitive function assessment, MMSE scores of $\geq 23$ indicated good cognitive function [7].

In the present study, the behavioural variables were smoking status, alcohol consumption, substance usage in the last 12 months, physical activity, daily consumption of fruits and vegetables and body weight. The body mass index (BMI) was calculated as weight $(\mathrm{kg}) /$ height squared $\left(\mathrm{m}^{2}\right)$. Respondents who exercised at least 150 minutes per week (with moderate intensity such as 30 minutes brisk walking at least five times per week) were categorized as physically active [8]. Respondents who answered the 8-item Duke-UNC Functional Social Support Questionnaire using a 5-point Likert scale (ranging from $1=$ much less than I would like, to $5=$ as much as I would like) and who scored $>30$ were considered to have good social support [9].

Respondents were considered to have barriers to healthcare if they answered 'yes' to at least one of the 11 items related to the cost of treatment, transportation problem, cost of transport, inadequate drugs or equipment at health facilities, inadequate health personnel skills, by health personnel, having other personal commitments or work, not knowing where to go, thinking they were 'not sick enough', and denial of healthcare [8]. In addition, respondents were assessed on their agreement with the statement 'I am well prepared for retirement' using a 4point Likert scale (definitely false, mostly false, mostly true and definitely true). Those who answered definitely true or mostly true were considered to have pre-retirement preparation.

\section{Data Analysis}

Bivariate analysis was conducted using the Pearson chi-square test and the Yates correction test for certain variables. The association between predictors and SA was assessed using Multiple Logistic Regression. The level of statistical significance for this study was $p$-value $<0.05$. Public servants aged 50 years old to 60 years old regardless of their working status whether permanent or contract basis were included in this study. Meanwhile, foreigners, those who were already on long medical leave and Ministry of Health employees were excluded.

\section{Ethics approval and consent to participate}

This study was approved by the Universiti Kebangsaan Malaysia Medical Centre (UKMMC) Ethics Committee and National Medical Research Registry (NMRR), Malaysia (NMRR-16-375-29271 (IIR)). All participants were approached, informed about the aim of this study, and asked for verbal and written consents. Once consented, the participants filled in the questionnaire.

\section{RESULTS}

\section{Sociodemographic Characteristics}

Table 1 shows the characteristics of the respondents. Of 1,064 respondents, the majority were married $(90.9 \%)$, Malay $(78.7 \%)$, female (72.9\%), aged $50-54$ years old $(64.5 \%)$ and professionals $(74.2 \%)$ with bachelor degree qualification (55.4\%). The mean age was $53.6 \pm$ 2.7 years. Most respondents had a monthly income of RM 5,600.00 and above $(634,59.6 \%)$ (they were categorised as high-income group). For the behavioural aspect, many respondents were physically inactive and had inadequate daily fruits and vegetables intake. In fact, $41.1 \%$ of the respondents were overweight. Eight hundred and thirteen respondents (76.4\%) perceived that they had good social support and 
almost all respondents claimed to have preretirement preparation $(1,024,96.2 \%)$. Only 57 respondents (5.4\%) had experienced barriers to obtaining healthcare.

Table 1a: Characteristics of respondents according to socio-demographic and other studied factors $(n=1,064)$

\begin{tabular}{|c|c|c|c|c|}
\hline Variable & $\mathbf{n}$ & $\%$ & Mean & S.D \\
\hline Age (year) & & & 53.60 & 2.7 \\
\hline 50 to 54 years old & 686 & 64.5 & & \\
\hline 55 to 60 years old & 378 & 35.5 & & \\
\hline \multicolumn{5}{|l|}{ Gender } \\
\hline Male & 288 & 27.1 & & \\
\hline Female & 776 & 72.9 & & \\
\hline \multicolumn{5}{|l|}{ Ethnic } \\
\hline Malay & 837 & 78.7 & & \\
\hline Chinese & 95 & 8.9 & & \\
\hline Indian & 123 & 11.6 & & \\
\hline Others & 9 & 0.8 & & \\
\hline \multicolumn{5}{|l|}{ Marital status } \\
\hline Single/Never married & 38 & 3.6 & & \\
\hline Married & 967 & 90.9 & & \\
\hline Separated & 4 & 0.4 & & \\
\hline Divorcee & 22 & 2.1 & & \\
\hline Widower & 33 & 3.1 & & \\
\hline \multicolumn{5}{|l|}{ Having children } \\
\hline Yes & 1009 & 94.8 & & \\
\hline No & 41 & 3.9 & & \\
\hline \multicolumn{5}{|l|}{ Educational level } \\
\hline Completed form 3 & 34 & 3.2 & & \\
\hline Completed form 5 & 135 & 12.7 & & \\
\hline Completed form 6/certificate/diploma & 167 & 15.7 & & \\
\hline Completed a bachelors degree & 589 & 55.4 & & \\
\hline Completed a masters degree & 124 & 11.7 & & \\
\hline Completed a doctoral qualification (PhD) & 6 & 0.6 & & \\
\hline Others & 9 & 0.8 & & \\
\hline \multicolumn{5}{|l|}{ Job category } \\
\hline Professionals & 790 & 74.2 & & \\
\hline Support staffs & 274 & 25.8 & & \\
\hline \multicolumn{5}{|l|}{ Employment status } \\
\hline Permanent & 1,061 & 99.7 & & \\
\hline Contract & 3 & 0.3 & & \\
\hline Monthly individual's income (RM) & & & $6,166.75$ & $2,324.12$ \\
\hline$<$ RM 2,300.00 & 38 & 3.6 & & \\
\hline RM 2,300.00-RM5,599.00 & 392 & 36.8 & & \\
\hline$\geq R M 5,600.00$ & 634 & 59.6 & & \\
\hline Median (IQR) & \multicolumn{3}{|c|}{$6,000(5,000,7,500)$} & \\
\hline Min - Max & \multicolumn{3}{|c|}{$800-21,677.00$} & \\
\hline
\end{tabular}


Table 1b: Characteristics of respondents according to socio-demographic and other studied factors $(n=1,064)$

\begin{tabular}{|c|c|c|c|c|}
\hline Variable & $\mathbf{n}$ & $\%$ & Mean & S.D \\
\hline \multicolumn{5}{|l|}{ Retirement scheme } \\
\hline Pension & 1,024 & 96.2 & & \\
\hline Employees Provident Fund (EPF) & 40 & 3.8 & & \\
\hline \multicolumn{5}{|l|}{ Body Mass Index (BMI) } \\
\hline$<18.5$ (underweight) & 23 & 2.2 & & \\
\hline $18.50-24.99$ (normal) & 385 & 36.2 & & \\
\hline $25.00-29.99$ (overweight) & 437 & 41.1 & & \\
\hline > 30.00 (obese) & 216 & 20.3 & & \\
\hline \multicolumn{5}{|l|}{ Smoking Status } \\
\hline Yes & 69 & 6.5 & & \\
\hline No & 754 & 70.9 & & \\
\hline \multicolumn{5}{|l|}{ Alcohol drinking } \\
\hline Yes & 55 & 5.2 & & \\
\hline No & 1,009 & 94.8 & & \\
\hline \multicolumn{5}{|l|}{ Physically active } \\
\hline Yes & 286 & 26.9 & & \\
\hline No & 778 & 73.1 & & \\
\hline \multicolumn{5}{|c|}{ Adequate daily consumption of fruits and vegetables } \\
\hline Yes & 237 & 22.3 & & \\
\hline No & 827 & 77.7 & & \\
\hline Perceived social support & & & 33.53 & 5.65 \\
\hline Good social support (score $>30$ ) & 813 & 76.4 & & \\
\hline Poor social support (score $\leq 30$ ) & 251 & 23.6 & & \\
\hline
\end{tabular}

For the criteria of SA, 471 respondents (44.3\%) had at least one of the six major chronic diseases; most had hypertension $(360,33.8 \%)$, followed by diabetes mellitus $(209,19.6 \%)$ and heart disease $(42,3.9 \%)$. Most respondents had good physical function $(869,81.7 \%)$. In terms of psycho-cognitive function, 790 respondents (74.2\%) had good psychological function and $100 \%$ of respondents had good cognitive function (mean MMSE score, $25.00 \pm 0.92$ range, 23-25). Overall, the analysis showed that the 790 respondents $(74.2 \%)$ had good psychocognitive functioning. This study showed that the prevalence of SA was $37.5 \%$, whereby only 399 respondents could fulfil all three criteria for SA. The distribution of the frequency and percentage of respondents according to the SA criteria fulfilled are summarised in Fig. 1

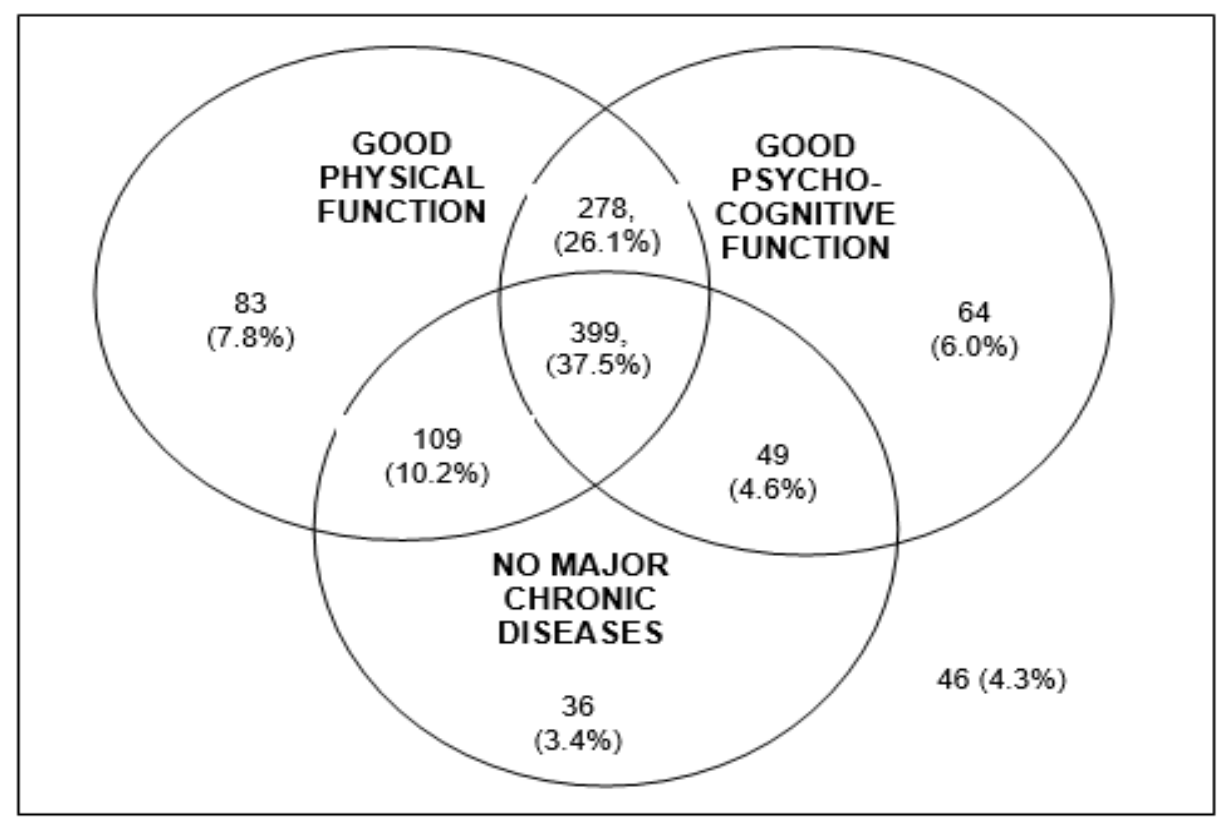

Note: No. of respondents, $n=83+278+399+109+64+49+36+46=1,064$

Fig.1: Distribution of the frequency and percentage of respondents according to the SA criteria fulfilled $(n=1,064)$ 
The bivariate analysis showed that the nonobese $\left(x^{2}=19.43, p<0.01\right)$, younger $\left(x^{2}=4.34\right.$, $\mathrm{p}=0.04)$ and physically active $\left(\mathrm{x}^{2}=6.43, \mathrm{p}=0.01\right)$ respondents experienced significantly more SA than their counterparts. Respondents with good social support $\left(x^{2}=12.95, \quad p<0.01\right)$ had significantly lower risk of becoming nonsuccessful agers (Table 2). There was no significant difference for other variables between respondents with or without SA.

Similarly, multiple logistic regression analysis proved that these variables were significant predictors for SA (Table 3). The non-obese respondents had 2.14 times higher odds for SA and respondents with good social support had 1.78 times higher odds for SA compared to their opposite counterparts. The younger and physically active respondents both had 1.3 times higher odds of SA than their opposite counterparts. None of the variables had significant interaction. The regression model was statistically stable, with variance inflation factor measurement $<10$. This model fit was based on a non-significant Hosmer-Lemeshow goodness-of-fit test $(p=0.91)$ and the overall percentage of $62.4 \%$ from the classification table. No influential outlier was noted.

Table 2a: Results of bivariate analysis using Chi-square test and Yates correction $(n=1,064)$

\begin{tabular}{|c|c|c|c|c|}
\hline \multirow{3}{*}{ Variable } & \multicolumn{2}{|c|}{ Successful aging (SA) } & \multirow{3}{*}{$\mathrm{x}^{2}$ value $(\mathrm{df})$} & \multirow{3}{*}{$\mathrm{p}$ value } \\
\hline & Yes & No & & \\
\hline & n (\%) & n (\%) & & \\
\hline \multicolumn{5}{|l|}{ Age (year) } \\
\hline 50 to 54 years old & $273(39.8)$ & $413(60.2)$ & $4.34(1)$ & 0.04 \\
\hline \multirow{2}{*}{\multicolumn{5}{|c|}{ Ethnic }} \\
\hline & & & & \\
\hline Bumiputera & $325(38.4)$ & $521(61.6)$ & $1.48(1)$ & 0.22 \\
\hline Non bumiputera & 74 (33.9) & $144(66.1)$ & & \\
\hline \multicolumn{5}{|l|}{ Gender } \\
\hline Male & $103(35.8)$ & $185(64.2)$ & $0.51(1)$ & 0.48 \\
\hline Female & $296(38.1)$ & $480(61.9)$ & & \\
\hline \multicolumn{5}{|l|}{ Marital status } \\
\hline In relationship & $366(37.8)$ & $601(62.2)$ & $0.55(1)$ & 0.46 \\
\hline Not in relationship & $33(34.0)$ & $64(66.0)$ & & \\
\hline \multicolumn{5}{|l|}{ Having children } \\
\hline Yes & $372(36.9)$ & $637(63.1)$ & $0.08(1)$ & 0.78 \\
\hline No & $16(39.0)$ & $25(61.0)$ & & \\
\hline \multicolumn{5}{|l|}{ Highest educational level } \\
\hline High & $272(37.8)$ & $447(62.2)$ & $0.10(1)$ & 0.75 \\
\hline Low & $127(36.8)$ & $218(63.2)$ & & \\
\hline \multicolumn{5}{|l|}{ Employment status } \\
\hline Permanent & $398(37.5)$ & $663(62.5)$ & $0.00^{*}(1)$ & $1.00^{*}$ \\
\hline Contract & $1(33.3)$ & $2(66.7)$ & & \\
\hline \multicolumn{5}{|l|}{ Job category } \\
\hline Professionals & $298(37.7)$ & $492(62.3)$ & $0.06(1)$ & 0.80 \\
\hline Support staffs & $101(36.9)$ & $173(63.1)$ & & \\
\hline \multicolumn{5}{|l|}{ Retirement scheme } \\
\hline Pension & $388(37.9)$ & $636(62.1)$ & $1.77(1)$ & 0.18 \\
\hline Employees Provident Fund (EPF) & $11(27.5)$ & $29(72.5)$ & & \\
\hline \multicolumn{5}{|l|}{ Monthly individual's income (RM) } \\
\hline High & $230(36.3)$ & $404(63.7)$ & $1.00(1)$ & 0.32 \\
\hline Low & $169(39.3)$ & $261(60.7)$ & & \\
\hline \multicolumn{5}{|l|}{ Smoking Status } \\
\hline Yes & $28(40.6)$ & $41(59.4)$ & $0.30(1)$ & 0.59 \\
\hline No & $371(37.3)$ & $624(62.7)$ & & \\
\hline \multicolumn{5}{|l|}{ Alcohol drinking } \\
\hline Yes & $18(32.7)$ & $37(67.3)$ & $0.56(1)$ & 0.45 \\
\hline No & $381(37.8)$ & $628(62.2)$ & & \\
\hline \multicolumn{5}{|l|}{ Physical activities } \\
\hline Active & $125(43.7)$ & $161(56.3)$ & $6.43(1)$ & 0.01 \\
\hline Not active & $274(35.2)$ & $504(64.8)$ & & \\
\hline \multicolumn{5}{|c|}{ Adequate daily consumption of fruits and vegetables } \\
\hline Yes & $85(35.9)$ & $152(64.1)$ & $0.35(1)$ & 0.56 \\
\hline No & $314(38.0)$ & $513(62.0)$ & & \\
\hline
\end{tabular}


Table 2b: Results of bivariate analysis using Chi-square test and Yates correction $(n=1,064)$

\begin{tabular}{|c|c|c|c|c|}
\hline \multirow{3}{*}{ Variable } & \multicolumn{2}{|c|}{ Successful aging (SA) } & \multirow{3}{*}{$\mathrm{x}^{2}$ value (df) } & \multirow{3}{*}{$p$ value } \\
\hline & Yes & No & & \\
\hline & n (\%) & n (\%) & & \\
\hline \multicolumn{5}{|c|}{ Body Mass Index } \\
\hline Non-obese & $346(40.8)$ & $502(59.2)$ & $19.43(1)$ & $<0.01$ \\
\hline Obese & $53(24.5)$ & $163(75.5)$ & & \\
\hline \multicolumn{5}{|c|}{ Social support } \\
\hline Good & $329(40.5)$ & $484(59.5)$ & $12.95(1)$ & $<0.01$ \\
\hline Poor & 70 (27.9) & $181(72.1)$ & & \\
\hline \multicolumn{5}{|c|}{ Barrier to get health care } \\
\hline Yes & $23(40.4)$ & $34(59.6)$ & $0.21(1)$ & 0.65 \\
\hline No & $376(37.3)$ & $631(62.7)$ & & \\
\hline \multicolumn{5}{|c|}{ Pre-retirement preparation } \\
\hline Yes & 388 (37.9) & $636(62.1)$ & $1.77(1)$ & 0.18 \\
\hline No & $11(27.5)$ & $29(72.5)$ & & \\
\hline
\end{tabular}

Table 3: Factors associated with SA among studied population using Multiple Logistic Regression $(n=1,064)$

\begin{tabular}{|c|c|c|c|c|c|c|c|c|}
\hline \multirow[b]{2}{*}{ Variable } & \multicolumn{4}{|c|}{ Slog $R^{1}$} & \multicolumn{4}{|c|}{$M \log R^{2}$} \\
\hline & Crude OR & $95 \% \mathrm{Cl}^{4}$ & $\begin{array}{c}x^{2} \text {-stat } \\
(\mathrm{df})^{\mathrm{a}}\end{array}$ & $\mathrm{p}$-value ${ }^{\mathrm{a}}$ & Adj $O R^{3}$ & $\begin{array}{c}95 \% \\
\mathrm{Cl}^{4} \\
\end{array}$ & $\begin{array}{c}x^{2} \text {-stat } \\
\text { (df) }\end{array}$ & p-value \\
\hline \multicolumn{9}{|l|}{ Age group } \\
\hline$<55$ years old & 1.32 & $\begin{array}{l}1.02- \\
1.72\end{array}$ & $4.38(1)$ & 0.04 & 1.32 & $\begin{array}{c}1.01- \\
1.73\end{array}$ & $5.39(1)$ & 0.02 \\
\hline$[\geq 55$ years old $]$ & 1.00 & & & & & & & \\
\hline \multicolumn{9}{|l|}{ Physical activities } \\
\hline Active & 1.43 & $\begin{array}{c}1.08- \\
1.88\end{array}$ & $6.36(1)$ & 0.01 & 1.39 & $\begin{array}{c}1.05- \\
1.84\end{array}$ & $4.32(1)$ & 0.04 \\
\hline [Not active] & 1.00 & & & & & & & \\
\hline \multicolumn{9}{|l|}{ Body weight status } \\
\hline Non-obese & 2.12 & $\begin{array}{l}1.51- \\
2.98\end{array}$ & $20.38(1)$ & $<0.01$ & 2.14 & $\begin{array}{l}1.52- \\
3.02\end{array}$ & $20.59(1)$ & $<0.01$ \\
\hline [Obese] & 1.00 & & & & & & & \\
\hline \multicolumn{9}{|l|}{ Social support } \\
\hline Good & 1.76 & $\begin{array}{l}1.29- \\
2.40\end{array}$ & $13.35(1)$ & $<0.01$ & 1.78 & $\begin{array}{l}1.30- \\
2.43\end{array}$ & $14.02(1)$ & $<0.01$ \\
\hline [Poor] & 1.00 & & & & & & & \\
\hline $\begin{array}{l}\text { Only variables with significant } \\
{ }^{1} \text { Simple Logistic Regression } \\
2 \text { Multiple Logistic Regression } \\
{ }^{3} \text { Adjusted odds ratio }\end{array}$ & $\begin{array}{r}\text { ts were } \\
4 C \\
a L \\
{[}\end{array}$ & $\begin{array}{l}\text { esented } \\
\text { idence in } \\
\text { ihood } R a \\
\text { Reference }\end{array}$ & $\begin{array}{l}\text { le table. } \\
\text { (al) } \\
\text { (LR) test }\end{array}$ & & & & & \\
\hline
\end{tabular}

\section{DISCUSSION}

Successful aging is not a new concept among researchers and many of them have continued to study it to seek the most ideal definition and also to identify any additional factors related to SA. In this study, we aimed to determine the prevalence and predicting factors of SA among public servants in Klang Valley. As we had adapted the 1987 model [2], thus we compared our findings with previous studies that applied a similar model. In terms of prevalence, some studies have shown that $10.1 \%$ of respondents are successful agers [10], and the prevalence may be up to $50 \%$ or more [11]. Meanwhile, the prevalence of SA in the present study was concordant with those studies and within that range, i.e. $37.5 \%$. When comparing our findings with previous local studies, the prevalence of SA among the older people (aged 60-80 years) was much lower at $13.8 \%$ [12]. This demonstrates the decreasing trend in the prevalence of SA as age increases. This is supported by a study that involved the younger age group population as respondents. In that study, the prevalence of SA was $50.1 \%$, for those aged $50-54$ years, $46.2 \%$, for those aged 55-59 years, $42.0 \%$ for those aged 60 years and above and only $37.2 \%$ for those aged 65 years and above [11]. The differences in the findings could be due to the difference in the theories or models used to study SA, differences between age groups or studied populations, as well as influences from the culture. 
In agreement with previous studies, we found that younger age, non-obese, being physically active and good social support were the four significant predictors for SA. By having normal BMI, regular exercise and social support distinguished people who continued to age successfully 4 years later from those who did not [13]. Apart from gender and occupation, age was a predictor for SA in one biomedical model [14]. Even though there was a large-scale review of SA among younger people, some studies produced the opposite findings. Despite experiencing latelife disability, some people still felt that they had aged successfully. This shows that lay person's perception of their aging might be different from researcher's understanding (with reference to the biomedical theories). This is because they tend to use adaptation and coping strategies to align their perception of SA with their experiences [15]. This is supported by a study that documented that older age was associated with lower likelihood of objectivelydefined SA, but with a greater likelihood of selfrated SA [16].

In the present study, non-obese respondents had 2.1 times higher odds of having SA, which is the highest odds ratio of all the predictors analysed. This association is consistent with a prior study [17]. Obesity has a negative impact on healthrelated quality of life. Even a small amount of weight loss ( 5 to $10 \%$ of the initial weight) is beneficial for both young and old people to prevent the adverse effects of obesity [18]. Thus, optimizing body weight and dietary intake are proposed as nutritional strategies towards reducing the risk of age-related chronic diseases. Previous studies have indicated that good social support is a significant predictor for SA [19]. As predicted, our results revealed similar findings. Among the various possible predictors analysed, good social support was the second strongest predictor for SA. Good social support can be obtained from spouse, family members, relatives, friends or neighbours. Higher levels of social support were beneficial for preventing depressive symptoms, thus maintaining or improving life satisfaction [20], which has a significantly positive impact on successful later years [21]. People who are able to visit their relatives and friends are more likely to be successful agers [22].

Similarly, to previous studies, being physically active was a significant predictor for SA in the present study. Physically active respondents are more likely to be rated as successful agers [23]. Being physically active continued to be an important significant determinant of selfperceived health into very late adulthood [24]. This is very important for improving balance, mobility and for preserving independence [25]. Healthy lifestyles since midlife have been proven to be associated with good overall health during aging. However, we could not determine the association between remaining sociodemographic and behavioural variables and SA in the present study. This is inconsistent with previous studies [26, 27]. A possible explanation for the discrepancy is that majority of our respondents were female and it is not a norm for Malaysian women to smoke or drink alcohol due to socio-cultural environmental influence [28].

We observed that the most difficult criterion of SA for our respondents to fulfil was 'having no major chronic disease', which has placed them into the non-successful agers category. This situation has contributed to a low prevalence of successful agers in this study. With reference to this finding, it could be interesting for future study if this group of respondents can be evaluated on their agreement (lay person's perception) of their aging as unsuccessful due to their chronic disease status. On the other hand, even though studies had agreed on the possibility for chronic illness and SA to coexist within the same individual $[29,30,31]$, efforts should be taken to highlight the importance of preventing chronic diseases to everyone. People should be clear that this statement is not meant to criticise or stigmatize whoever does not meet the model's definition of SA but instead to emphasize that every pre-retirement age group adult should have awareness and knowledge of their own health or medical status. Subsequently, actions should be taken to improve it by having regular health screenings and practicing healthy lifestyles. Employers play a role in providing a healthy working environment and carrying out promotional activities on SA. Apart from the roles of health professionals, the goals towards higher prevalence of SA in the future can be achieved if everyone plays their part in improving their wellbeing.

Involving the pre-retirement population group as respondents could yield better understanding of SA. Based on the findings of this study, more focused intervention can be implemented in this group. Meanwhile, the limitation of this study is that people with underlying medical problems who were already on long medical leave and who had retired early from government service had already been excluded from the sampling stage. Therefore, there is possibility of over or underestimation of the total percentage of successful agers within the studied population. Despite being particular during the sampling stage in the selection of respondents to avoid selection bias, majority of respondents were noted to be Malay women. Although this figure might be able to represent the federal government public servants fairly, it doesn't reflect similar distribution of each ethnic available in Malaysian. Apart from that, very few respondents reported any involvement in unhealthy behaviours such as smoking and alcohol consumption. In view of this, there is 
possibility of underestimation in some of the association reported for the predictors of SA in this present study.

\section{CONCLUSION}

The prevalence of SA in this study is $37.5 \%$ and the associated factors identified were younger age, non-obese, being physically active and had good social support. A health-conscious attitude and the practice of healthy lifestyles should be inculcated among pre-retirement public servants to prepare them for SA. Apart from that, it would be best to apply bio-psychosocial theories, spiritual aspect and layperson's perspective on aging in studying SA to obtain a broader picture in this regard among the general population.

\section{Abbreviations}

Body Mass Index (BMI); Cl: Confidence interval; Max: Maximum; Min: Minimum, OR: Odds ratio; S.D: Standard deviation, SA: Successful aging.

\section{ACKNOWLEDGEMENTS}

We would like to express our gratitude to all the agencies and the participants for participating in this study.

\section{Funding}

Not applicable.

\section{Competing interests}

The authors declare that they have no competing interests.

\section{REFERENCES}

1. DOS. Population Quick Info. Department of Statistics, Malaysia. 2019.

http://pqi.stat.gov.my/searchBI.php.

2. Rowe JW, Kahn RL. Human aging: usual and successful. Science 1987;237(4811):143-9.

3. Moeini M, Sharifi S, Zandiyeh Z. Does Islamic spiritual program lead to successful aging? A randomized clinical trial. J Educ Health Promot 2016;5(1):2.

4. Glatt SJ, Chayavichitsilp P, Depp C, et al. Successful aging: from phenotype to genotype. Biol Psychiatry 2007;62:282293.

5. Holmes J, Powell-griner E, Lethbridgecejku $M$, et al. Aging Differently: Physical Limitations Among Adults Aged 50 years and Over: United States, 2001 - 2007. NCHS Data Brief. 2009;(20):1-8.

6. Musa R, Ramli R, Abdullah K, et al. Concurrent validity of the depression and anxiety components in the Bahasa Malaysia version of the Depression Anxiety and Stress scales (DASS). ASEAN $J$ Psychiatry 2011;12(1):66-70.

7. Almeida OP, Norman P, Hankey $G$, et al. Successful mental health aging: results from a longitudinal study of older Australian men. Am J Geriatr Psychiatry 2006;14(1):27-35.

8. Institute of Public Health (IPU). National Health and Morbidity Survey 2011 (NHMS 2011). Vol.1: Methodology and General Findings 2011;1:258.

9. Yang $H$, Shin $D$, Park J, et al. The Association Between Perceived Social Support and Continued Smoking in Cancer Survivors. Japanese $J$ of Clin Oncology 2013;43(1):45-54.

10. McLaughlin SJ, Connell CM, Heeringa SG, et al. Successful aging in the United States: prevalence estimates from a national sample of older adults. J Gerontol Soc Sci 2010;65B(2):216-226.

11. Meng X, D'Arcy C. Successful aging in Canada: Prevalence and predictors from a population based sample of older adults. Gerontology 2014;60:6572.

12. Hamid TA, Yadollah Abolfathi Momtaz RI. Predictors and Prevalence of Successful Aging among Older Malaysians. Gerontology 2012;58:36670.

13. Pruchno RA, Wilson-Genderson M. A Longitudinal Examination of the Effects of Early Influences and Midlife Characteristics on Successful Aging. J Gerontol B Psychol Sci Soc Sci 2015;70(6):850-9.

14. Tzioumis E, Avila J, Adair L. Determinants of Successful Aging in a Cohort of Filipino Women. Geriatrics 2019;4(1):12.

15. Romo RD, Wallhagen MI, Yourman L, et al. Perceptions of successful aging among diverse elders with late-life disability. 2013;53(6):939-49. Gerontologist

16. Gu D, Feng Q, Sautter JM, et al. Concordance and discordance of selfrated and researcher-measured successful aging: Subtypes and associated factors. J Gerontol B Psychol Sci Soc Sci 2017;72(2):214-27. 
17. Shi WH, Zhang HY, Zhang J, et al. The status and associated factors of successful aging among older adults residing in longevity areas in China. Biomed Environ Sci 2016;29(5):347-55.

18. Zamboni M, Mazzali G, Zoico E, et al. Health consequences of obesity in the elderly: a review of four unresolved questions. Int J Obes 2005;29(9):101129.

19. Dorji L, Pornchai Jullamate, Rarcharneepon Subgranon ER. Predicting Factors of Successful Aging among Community Dwelling Older Adults in Thimphu, Bhutan. Bangkok Med J 2019;15(1):38-43.

20. Adams TR, Rabin LA, Da Silva VG, et al. Social Support Buffers the Impact of Depressive Symptoms on Life Satisfaction in Old Age. Clin Gerontol 2016; 39(2):139-57.

21. Shin K-Y, Ko J-U. Influence of Elderly People's Lifestyle on Successful Aging. J Korea Contents Assoc 2015;15(9):24356.

22. $\mathrm{Li} \mathrm{Cl}$, Lin $\mathrm{CH}$, Lin WY, et al. Successful aging defined by health-related quality of life and its determinants in community-dwelling elders. BMC Public Health 2014;14(1):1013.

23. Gopinath B, Kifley A, Flood VM, et al. Physical Activity as a Determinant of Successful Aging over Ten Years. Sci Rep 2018;8(1):2-6. http: / /dx.doi.org/10.1038/s41598-01828526-3

24. Cherry AKE, Brown JS, Kim S, et al. Social Factors and Healthy Aging: Findings from the Louisiana Healthy Aging Study (LHAS). Hum Kinet Journals 2016;5(1):50-6.

https://doi.org/10.1123/kr.2015-0052

25. Hernandez DC, Johnston CA. Individual and Environmental Barriers to Successful Aging: The Importance of Considering Environmental Supports. Am J Lifestyle Med 2016;11(1):21-3. https://doi.org/10.1177/15598276166 72617\%0A

26. Bosnes I, Nordahl HM, Stordal E, et al. Lifestyle predictors of successful aging: A 20-year prospective HUNT study. PLoS One 2019;14(7):1-8.

27. Daskalopoulou C, Koukounari A, Wu YT, et al. Healthy ageing trajectories and lifestyle behaviour: the Mexican Health and Aging Study. Sci Rep 2019;9(1):110.

28. Tsai ACH, Lin YA, Tsai HJ. Predictors of smoking cessation in 50-66-year-old male Taiwanese smokers: A 7-year national cohort study. Arch Gerontol Geriatr 2012;55(2):295-300.

29. Alkhodary AA, Syed Mohamed Aljunid, Ismail A et al. The Economic Burden of Frailty among Elderly People: A Review of The Current Literature. Malaysian Journal of Public Health Medicine 2020, Vol. 20 (2): 224-232.

30. Young Frick KD, Phelan EAY. Can successful aging and chronic illness coexist in the same individual? A multidimentional concept of successful aging. J Am Med Dir Assoc 2009;10:8792.

31. Parslow RA, Lewis VJ, Nay R. Successful aging: Development and testing of a multidimensional model using data from a large sample of older Australians. $J$ Am Geriatr Soc 2011;59(11):2077-83. 